\title{
Fatigue behaviour of HIPed and stress relieved Ti6Al4V alloy specimens produced by SLM
}

\author{
Joel da Silva de Jesus ${ }^{1}$, Luis Borrego ${ }^{2}$, José Ferreira ${ }^{3}$, Jose Costa ${ }^{3}$, and Carlos Capela ${ }^{4}$ \\ ${ }^{1}$ Universidade de Coimbra Departamento de Engenharia Mecanica \\ ${ }^{2}$ ISEC, Polytechnic Institute of Coimbra \\ ${ }^{3}$ University of Coimbra \\ ${ }^{4}$ Instituto Politecnico de Leiria Escola Superior de Tecnologia e Gestao
}

October 31, 2020

\begin{abstract}
Fatigue behaviour of HIPed and stress relieved Ti6Al4V alloy specimens produced by SLM was analysed (Re = -1). The HIP process caused a microstructural transformation decreasing the hardness and monotonic properties that not allowed fatigue strength increase. A bilinear behaviour in the elastic strain-fatigue life curve was observed, because of Young's modulus decrease during the cyclic elasto-plastic tests consequence of subgrains formation. The Smith-Watson-Topper and total strain energy density models showed a good concordance between predicted and experimental fatigue lives in notched samples.
\end{abstract}

\section{Hosted file}

Manuscrit.pdf available at https://authorea.com/users/371799/articles/490011-fatiguebehaviour-of-hiped-and-stress-relieved-ti6al4v-alloy-specimens-produced-by-slm 


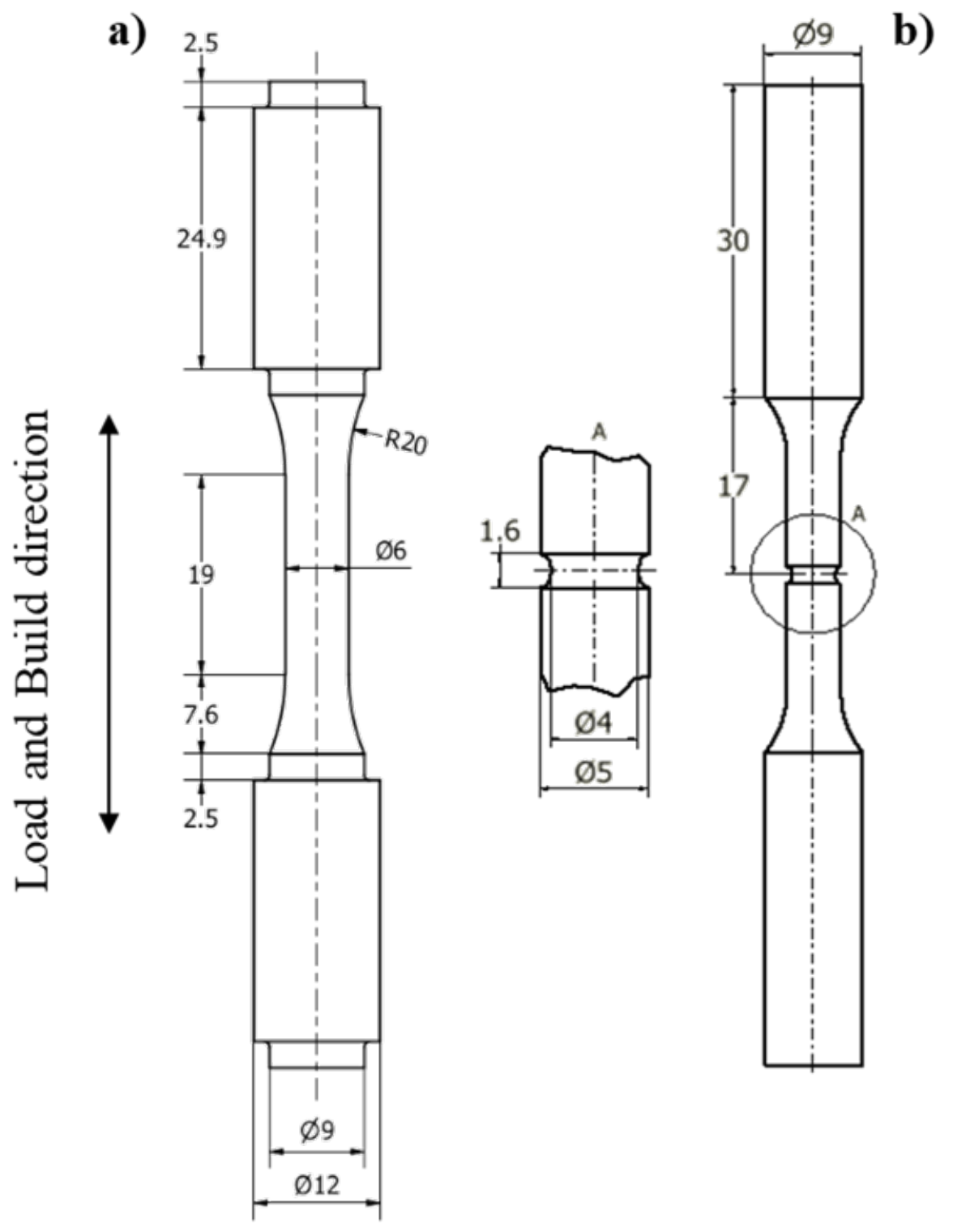



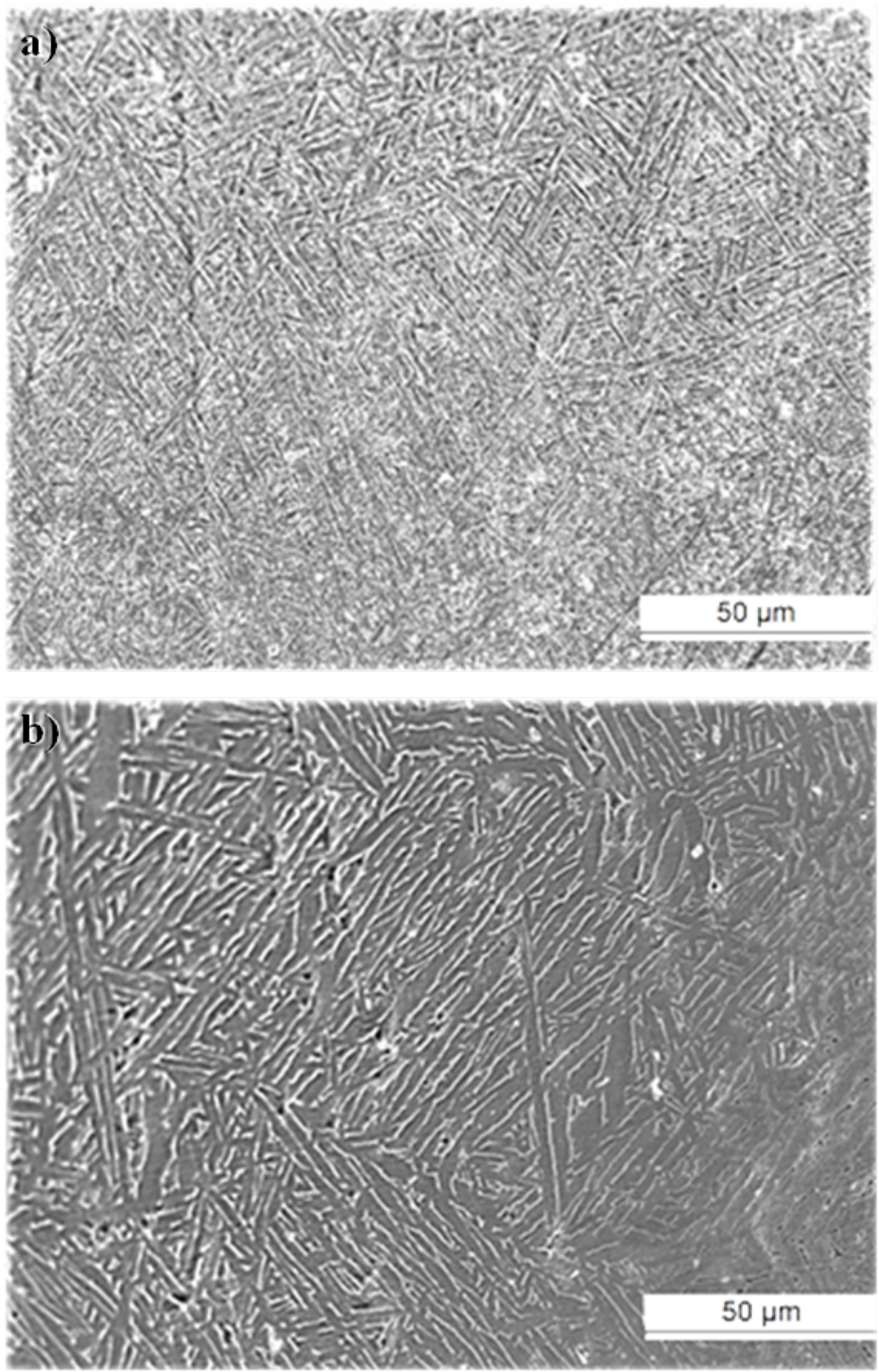

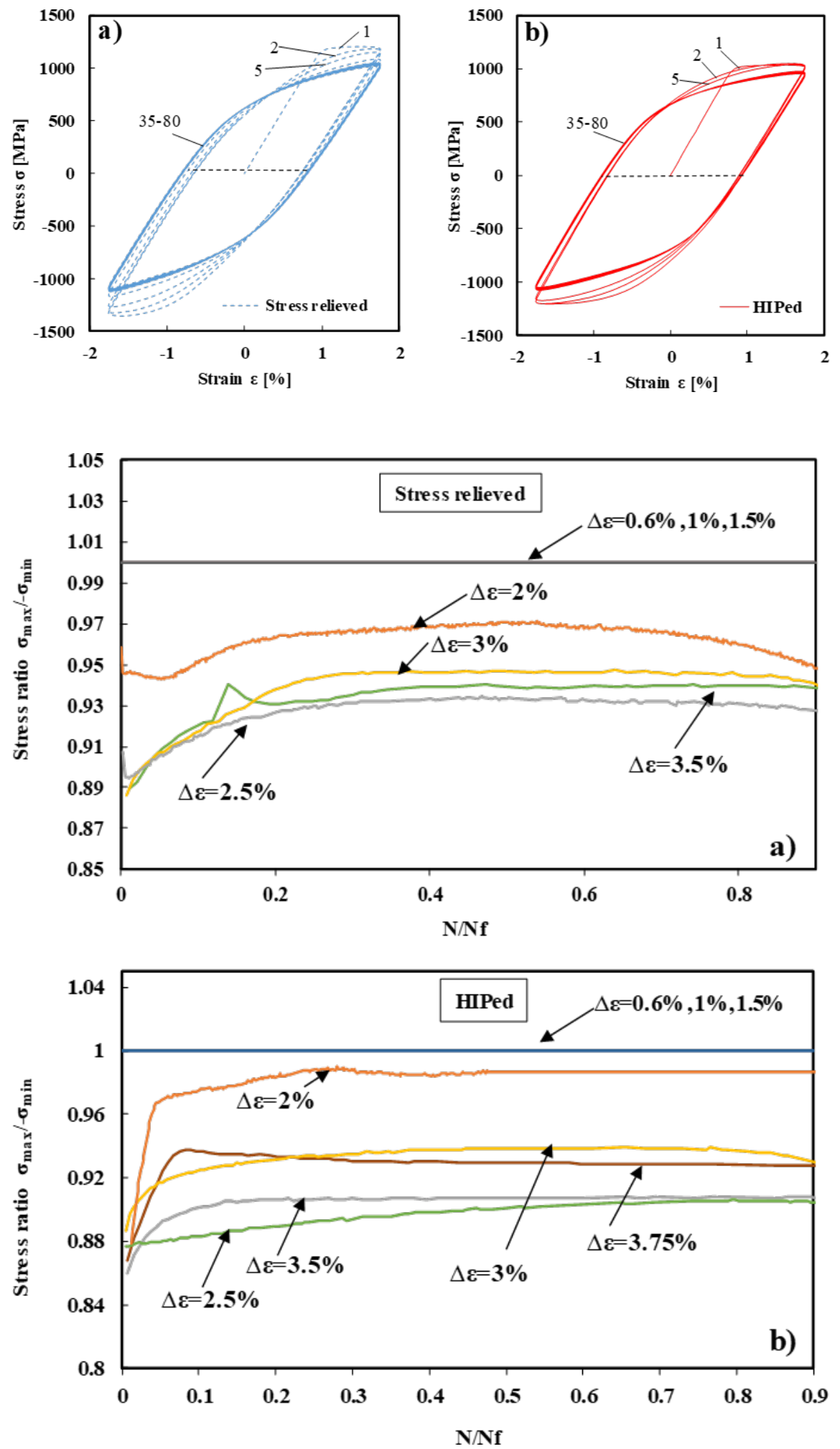

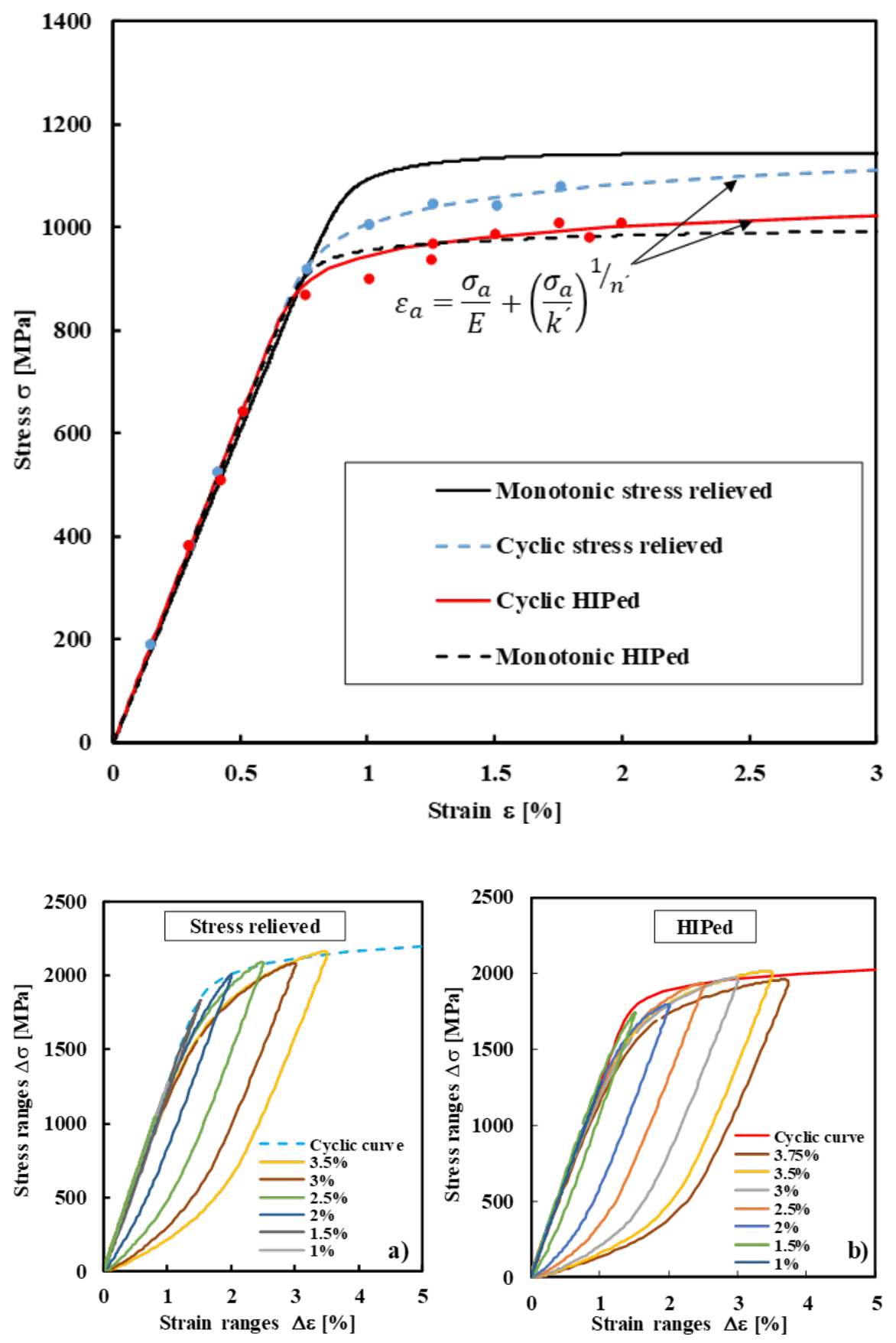

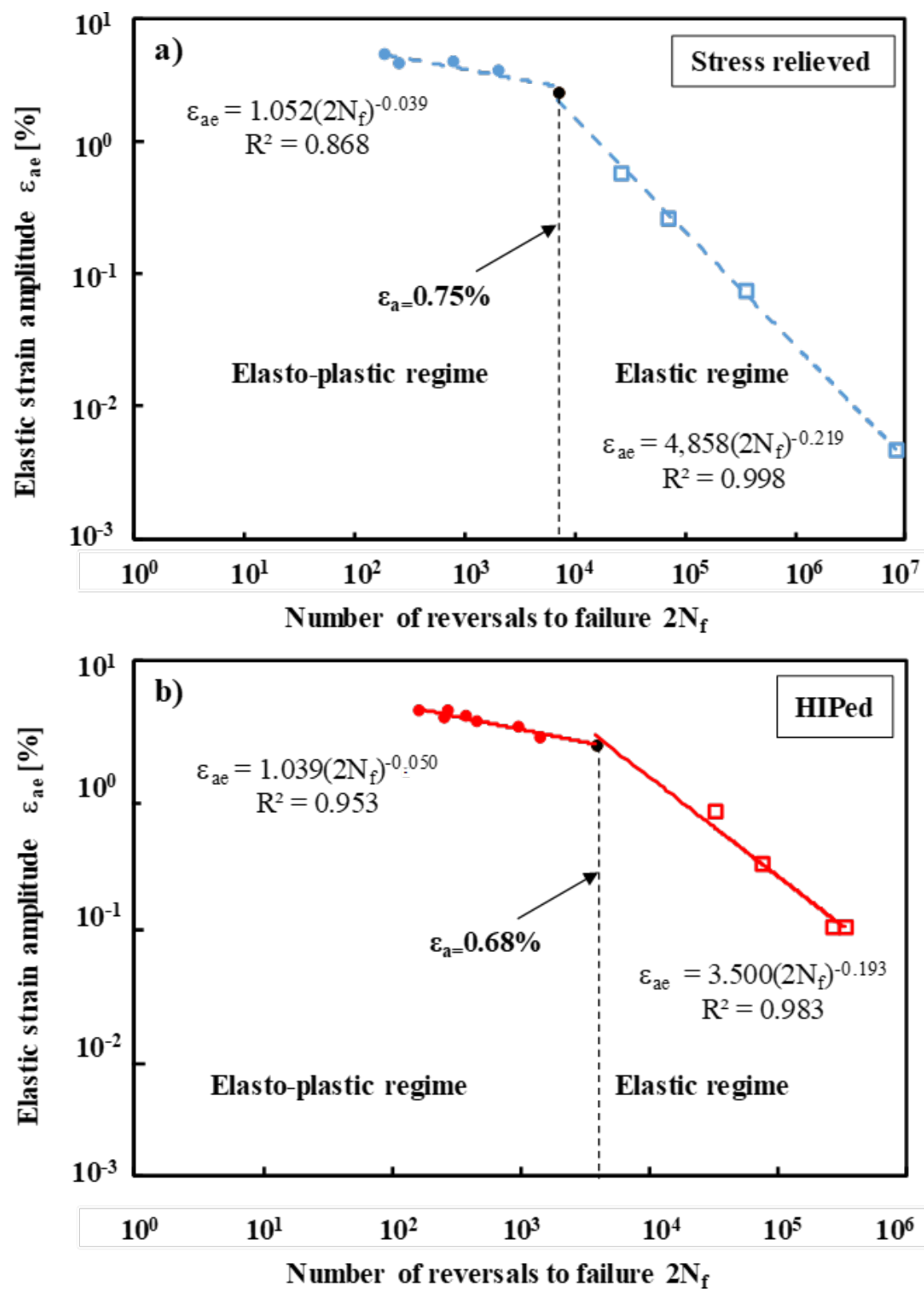

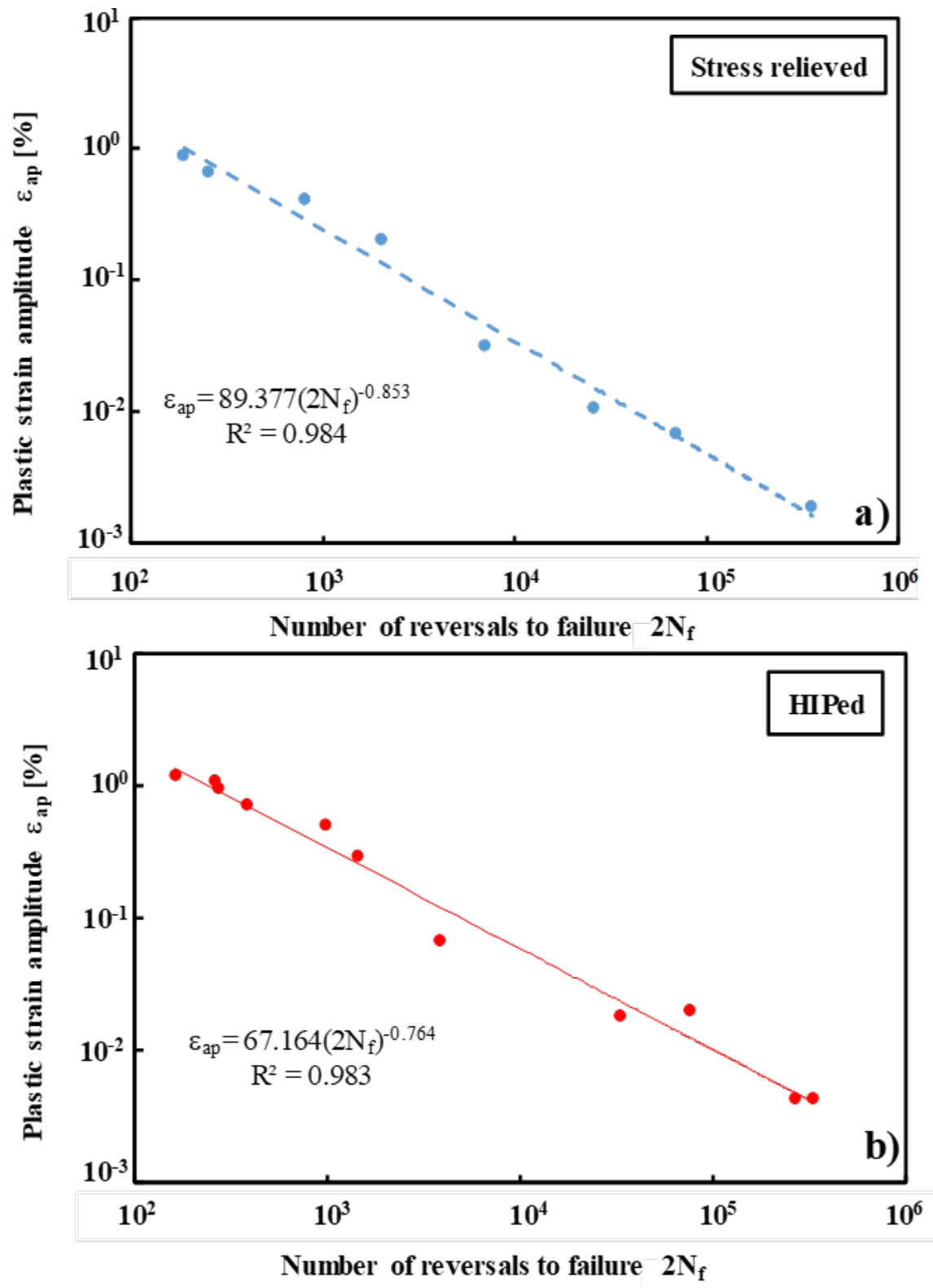


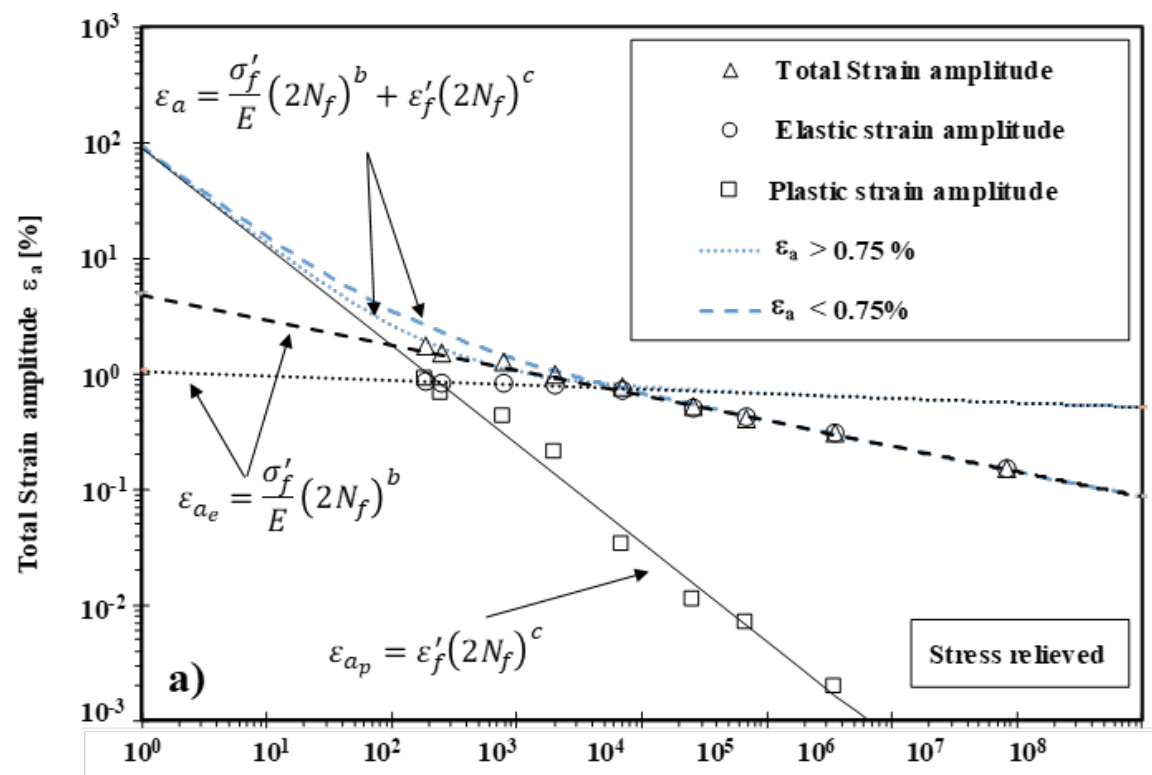

Number of reversals to failure $2 \mathrm{~N}_{\mathrm{f}}$

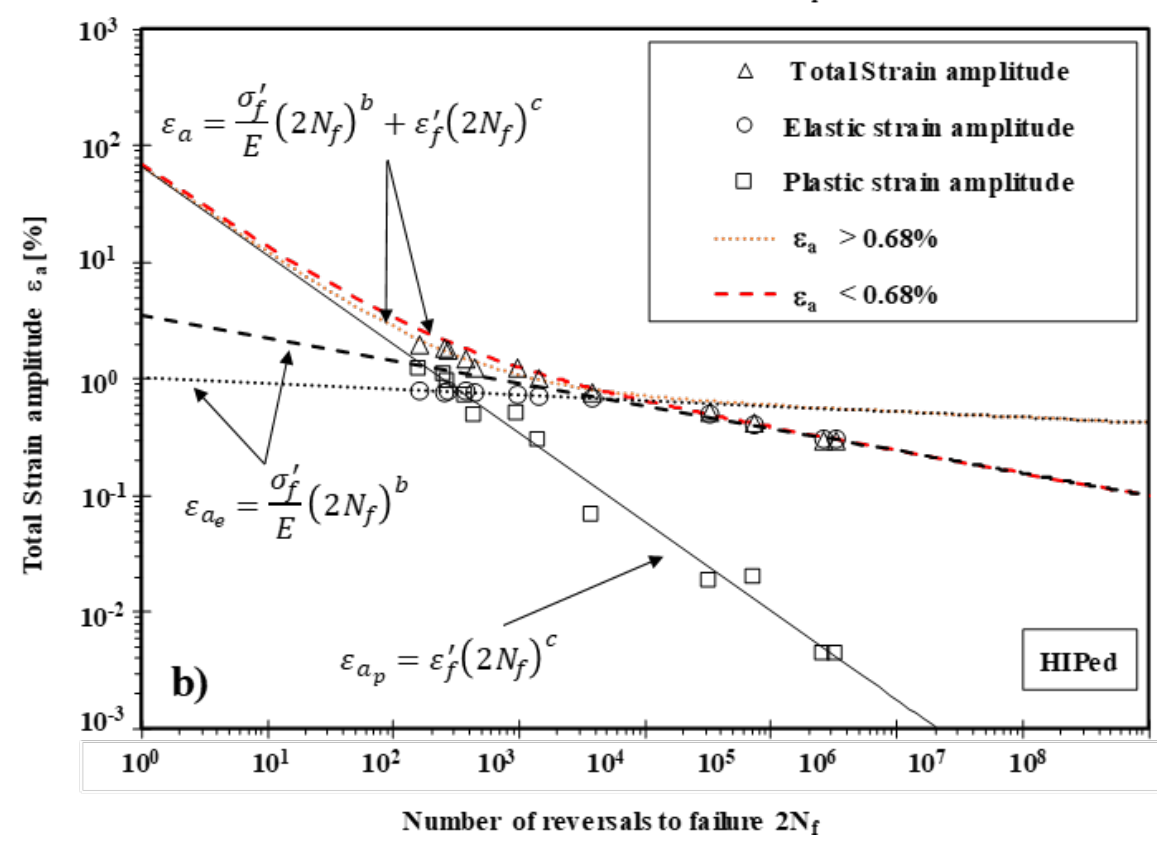



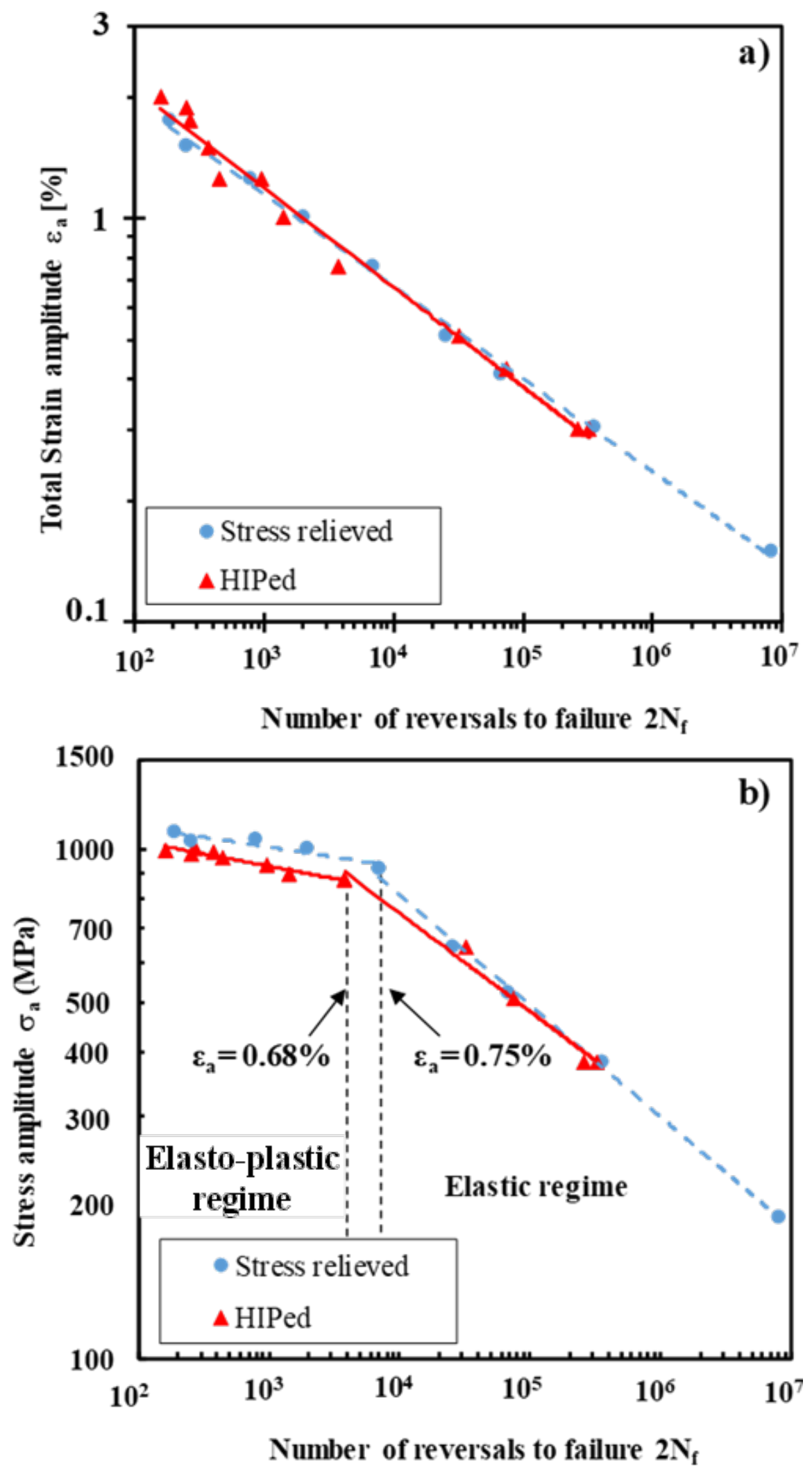

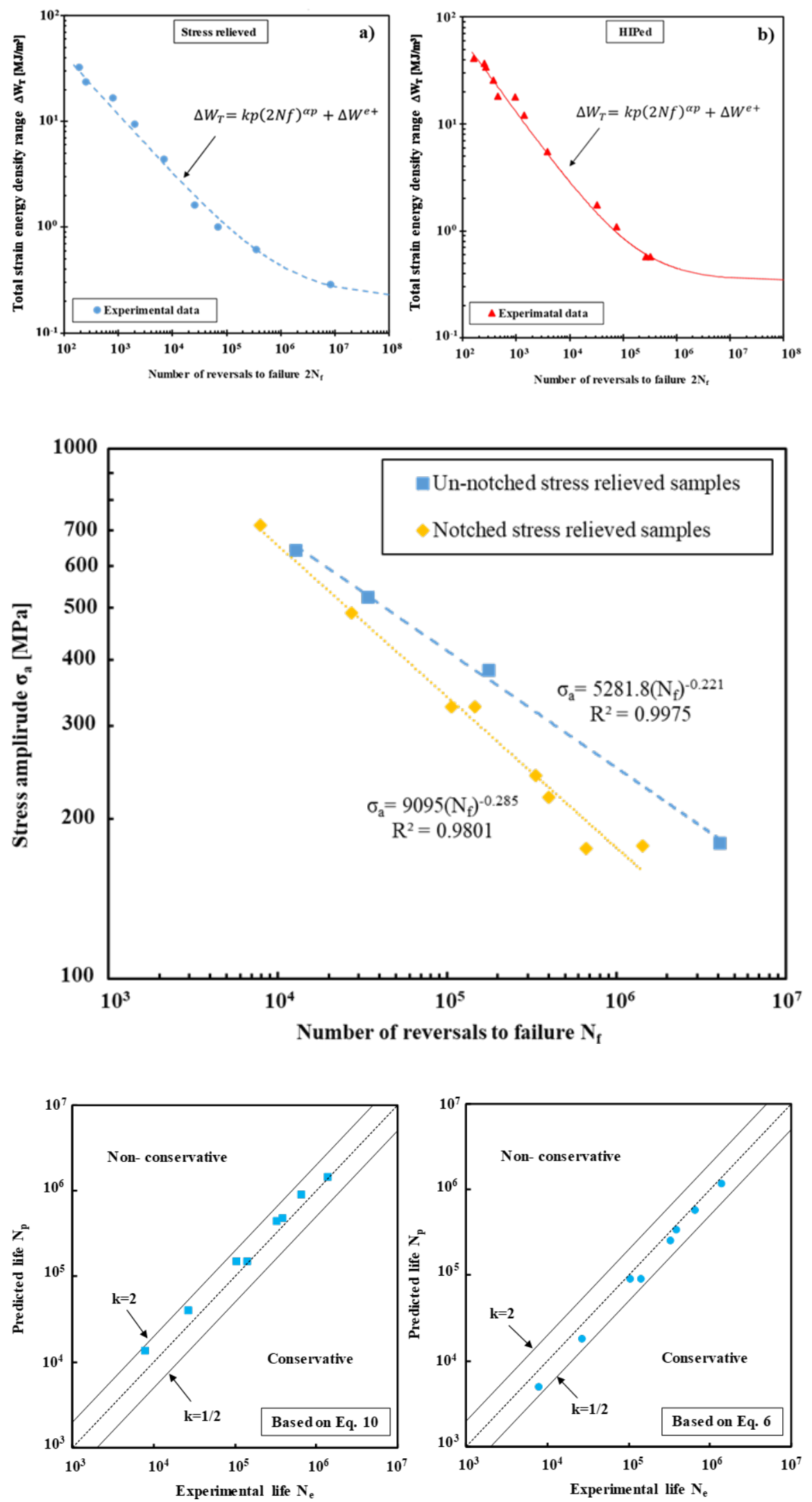